DOI 10.37882/2500-3682.2020.05.06

\title{
КОММУНИКАТИВНАЯ СОЦИАЛЬНОСТЬ - К РАЗДЕЛУ НЕКЛАССИЧЕСКАЯ ТЕОРИЯ УПРАВЛЕНИЯ
}

\section{COMMUNICATIVE SOCIALITY - TO THE SECTION NON-CLASSICAL CONTROL THEORY}

\section{N. Krivovyaz}

Summary: This article discusses the issues of non-classical control theory. Non-classical philosophy formed the construct "ontology of communicative sociality". Society became different, and this was reflected in the interest of analysts in such a characteristic of sociality as its communicative nature. Management itself is interpreted as the management of communicative in its essence and in nature relations. The situation has changed in the conditions of the transformation of the vector of modern ontology in the direction of communicativeness - in these conditions, communications are turned into the subject of management, management becomes communicative, focused on specific segments of the social.

Keywords: theory of management, communication, sociality, selfgovernment, communicative society, information society, non-classical theory of management.
Кривовяз Наталья Викторовна

Ассистент, Национальный исследовательский Томский политехнический университет awatanchik@yandex.ru

Аннотация: В данной статье рассмотрены вопросы неклассической теории управления. Неклассической философией был сформирован конструкт «онтология коммуникативной социальности». Общество становилось иным, и это нашло отражение в интересе аналитиков к такой характеристике социальности, как ее коммуникативный характер. Неклассическая управленческая культура сосредоточила внимание на контекстах и ситуационном характере реальности, отказавшись от ставших всеобщими схем, - это позволило сделать предметом управления в том числе и периферийные структуры. Управлению начали привлекаться сотрудники организации, и был использован потенциал самоорганизации и самоуправления.

Ключевые слова: теория управления, коммуникации, социальность, самоуправление, коммуникативное общество, информационное общество, неклассическая теория управления.
$\mathrm{P}$ убеж XX-XXI в.в. трансформировал парадигму управления. Фурор произвела работа создателя так называемой теории коммуникативного действия Ю. Хабермаса «Теория коммуникативного действия» (1981 г.), хотя о проблеме противопоставления сфер инструментального действия (сфера труда с ее критериями эффективности) и действия коммуникативного (представленного как взаимодействие, основанное на нормах и упорядоченное в соответствии с этими нормами) ставилась Ю. Хабермасом и ранее - до появления обозначенной работы. В то время как инструментальное действие ориентировано на успех, в основание коммуникативного действия положено взаимопонимание индивидов. Ю. Хабермасом использовано в обосновании интуиций, заложенных в теорию коммуникативного действия, и интерпретация различия инструментальной рациональности (понятие, ранее применяемое М. Вебером) и рациональности коммуникативной, как интерпретация четырех типов действий: стратегического (в него входит инструментальное действие), норморегулирующее, экспрессивное (Ю. Хабермасом оно названо драматургическим) и соответственно коммуникативное.

Позднее, в работе 1984 года «Vorstudien und Erganzungen zur Theorie dis Kommunikatiren Handelns», Fr./ M. 1984 Ю. Хабермас использует и понятие «пожиз- ненного мира», раскрывая роль жизненного мира в формировании среды, пространства коммуникативного действия: «Жизненный мир обладает не только функцией формирования контекста коммуникативного действия. Одновременно это резервуар, из которого участники коммуникации черпают убеждения, чтобы в ситуации возникшей потребности во взаимопонимании предложить интерпретации, пригодные для достижения консенсуса. В качестве ресурса жизненный мир конститутивен для процессов взаимопонимания ... мы можем представить себе жизненный мир, поскольку он привлечен к рассмотрению в качестве ресурса интерпретаций, как организованный в языке запас изначальных допущений, предпочтений, которые воспроизводятся в виде культурной традиции» [1]. Здесь Ю. Хабермас говорит о роли коммуникативного действия в укреплении традиций, в обновлении культурного потенциала, в формулировании солидарности, выступающей и Ю. Хабермаса в качестве источника социальной интеграции.

Эта формируемая традиция, - управлять внепредметной, неустойчивой, постоянно меняющейся социальностью, - не была характерна для классических теорий управления, она (традиция) являет себя сегодня, на рубеже XX-XXI в.в., как новая примета нового времени, - времени «неклассического». В ранее созданной фило- 
софии управления управление было отождествлено с властью - «... философия управления репрезентировала себя как философия власти. В таком качестве, то есть в направлении придания управлению характера жесткого администрирования, строго логических и рационально выверенных шагов, управленческих указаний и директив, она разрабатывалась и философами, и социологами. Поскольку шагам, ходам, способам не надо было меняться, ибо не менялись социальные контексты, и объект управления оставался в своем предметном содержании одним и тем же, то философия управления приобрела вид рационально устойчивого, никогда не меняющего своей сути и содержания бюрократического действия» $[2]$.

Концепция современной философии управления формируется, исходя из обширного эмпирического материала, поставляемого такими сферами, как социология управления (Г. Саймон, Ч. Бернард), теория организационного поведения (Р. Мак-Кинли), П. Дизель), социология труда (Д. Круз), психологии организаций и групп (Б. Джонсон, Р. Бэрон). Огромна и роль теоретических разработок, в которых исследуются проблемы специфики онтологии социальности «неоклассического времени», в том числе постмодернистской социальности.

В условиях информационного общества управление «работает» в направлении тех методологических подходов к исследованию социальности и культуры, которые способны инициировать отказ от фундаментализма, логоцентризма и других унифицированных конструкций, - формируется управленческая парадигма, осуществляющая переход от управления статикой к управлению движением. Проблема заключена в том, чтобы осмыслить те социокультурные контексты, в пределах которых совершается трансформация принципов управления, направленная на мобильность как характеристику коммуникативного общества, трансформация, ориентированная на переход стратегий управления: от управления статикой к управлению развитием. Лишь будучи трансформированными, теория и практика управления окажется способной принять необходимость увидеть объект, находящийся в движении, развитии, изменении, - это будет релевантное по своей сути управление. И сегодня авторы, исследующие феномен управления, видят свою задачу в том, чтобы отыскать в управленческой деятельности тот потенциал, что позволяет управленческим действиям быть ориентированным не на унифицированную статику, но на современное состояние множественности форм, изменяющихся, находящихся в процессах непрерывных трансформаций. Общество нуждается в новых механизмах управления. Для выработки этих механизмов важным является и учет специфики культуры современного общества, - коммуникативного, информационного. Эта культура характеризуется мобильностью и изменчивостью. В. Лехцнер, Ж. Тощенко, С. Смирнов пишут о современной культуре как культуре изменений, того «перехода, который никуда не переходит». М.А. Гусаковский, Л.А. Ященко, С.В. Костюкевич пишут о культуропорождении в мобильной и изменчивой культуре, о культурной бездоминантности, - эти явления провоцировали неоднолинейность и самоорганизацию.

Одной из предпосылок того, что управление в условиях информационно-коммуникативного общества не может исходить из ранее сложившихся теоретических установок, является то обстоятельство, что в условиях новой культуры (культуры постоянных изменений, культуры бездоминантной) меняется и человек. Исследователи пишут о кризисе его идентичности, личностной многоликости, что характерно для среды, создающей все новые образцы (Р. Сеннет, Н.В. Чиркова, Г.И. Петрова). В культуре, утрачивающей однолинейность и многомерность развития, расставшейся, по сути, с жадной логикой своего развития, формируется и иной человек. Р. Рорти называет его «человеком ироничным», Ж. Делез - «человеком-ризомой», Ж. Липовецки - «человеком-маской». Эта ситуация в аналитической литературе формирует новые подходы к теории управления (Школа культурной политики, «корпоративная культура», менеджмент). Методологические вопросы управления разрабатывают отечественные ученые В. Диев, С. Чернышева, С. Степанов, П.Г. Щедровицкий, В. Шепель, И. Богачек, в числе западных авторов - М. Кастельс, Ю. Хабермас, П. Друкер, М. Фуко, Д. Белл. Классические теории управления (тейлоризм) и ранее подвергались критике (Э. Мэйо). Сегодня критика осуществляется П. Друкером (концепция «самоуправляющегося коллектива»), К. Нордстремом и Й. Риддерстрале («управление в стиле фанк»), Р. Уотерманом («управление через ценности»). В предмет анализа превращены новые структуры управления (П. Друкер), корреляция управления и национальной культуры (В. Пронников), разграничение управления и власти (М. Фуко, К. Гаджиев, В. Ильин, А. Панарин и др.). Отличаясь прагматикой, эта литература помогает бизнесу в выстраивании конкурентных отношений.

Теория управления - специфическая сфера управленческого знания, содержание теорий управления всегда ориентирована на историко-культурный контекст. Культура управления определена контекстом, - культура управления зависима от ментальных, философских, религиозных, мировоззренческих установок и архетипов конкретной эпохи.

Если попытаться взглянуть на управление в историческом аспекте, очевиден вывод о том, что управление зарождалось как власть. Основанием властных отношений была культурная идеологема единого мира. В. Россман, анализируя традиционные цивилизации с присущим им порядком (космическим, социальным), утверждает и основание этих порядков - порядок был основан на 
идее Axis-Munadi (Центра мира); Axis Munadi - метафора культуры. Центр, обладая потенциалом центростремительной силы, объединял сегменты периферии, был средоточием зон периферии и формировал баланс «тех сил, которые определяли специфику традиционных цивилизации, - эстетическую, нравственную, политическую, религиозную. Центр был средоточием духовности цивилизации; исчезал центр - исчезала сбалансированность: центр служил тем элементом, который собирал вокруг себя членов сообщества, определял формы общения, взаимодействия, социального обмена. Ритуалы центра способствовали снятию напряжения между различными полюсами культуры и включали в себя символы общественного единения и священного брака. Статус человека в значительной степени определялся дистанцией и отношением к центру в социальном пространстве. Центр представлял собой модель самоидентификации. В нем аккумулировались духовные устремления носителей традиции, характер их доминирующего отношения к миру» [3]. В культурной традиции Эллады центром считался театр, театр как храм, сакральное пространство, божественный (теос) трон (тронос) - театрон. Роль Ахіs Munadi в эпоху средних веков исполнял Бог, священное писание, книга. Центр был тем сакральным по своей сути, что открывало дорогу на него. Именно на подобном представлении о Центре формировалась и культура управления, ее исходной установкой являлось понятие власти. В практике обыденности понятия «власть» и «управление» не были разграничены. И власть, и управление были связаны воедино вертикалью отношений, объединены в отношении «господство-подчинение»; и власти, и управлению была присуща иерархичность.

Следует отметить, что классические теории управления вполне отвечали специфике классических концепций управления, - об этом пишет Н.В. Чиркова: «... классическому времени - устойчивому, имеющему единую целенаправленность в своем движении, прогнозируемому в идеалах и нормах - вполне соответствовали властные и единые линейно-функциональные установки, и алгоритмические действия в управлении: приказания, жесткость распоряжений сверху, подчинение. Устойчивая социокультурная реальность вполне могла быть управляемой на основе единства администрирования и строгости идеологических приказов».

Однако ситуация изменилась в обществе, обозначенном как постиндустриальное, в том контексте, в котором воплощен иной, современный тип социокультурного развития, где в реальность превращена децентрация связей, социальной структуры, экономики. Н.В. Чиркова отмечает о феноменах постиндустриального общества - о власти и управлении в ситуации и структурах мира повседневности: «Термин «децентрация» пришел из области философии, которая рефлексирует по поводу обнаруживших свое значение новых признаков культур- ного состояния социальной реальности - утрата собирающего ее в единство центра-предела и, как следствие, - «расколотость», фрагментарность, центробежность не стоящей на пределе неопределенной культуры. Культура рассыпалась, приобрела облик поликультурных или межкультурных процессов. М. Фуко отмечает, что власть стала вездесущей, «распространяется непосредственно на повседневную жизнь ... классифицирует индивидов по категориям, характеризует их через их собственную индивидуальность», создает новую форму «пастырской власти» [4, с. 167-174]. «Подлинная природа такой власти - в модусе самосокрытия, она растворена по поверхности и в повседневности, обнаруживает себя на любом микроуровне социального» [4, с. 18].

Управление в постиндустриальном, информационно-коммуникативном обществе приобрело такие характеристики, как сложность и нелинейность. Выше мы отмечали, что об этом одним из первых писал Д. Белл в «Опыте социального прогнозирования» - автор говорил об «управлении организованными множествами - с большим числом переменных, комплексными организациями и системами, требующими координации деятельности сотен тысяч и даже миллионов людей» [5, с. 331333], понимая под организованными множествами ни единую культуру и видя в этом процессе децентрации культуры стадии постиндустриализма основание, - этим основанием является процесс трансформации знания в информацию, пришедшей на смену (в своих статусных проявлениях) таким категориям, как материальное производство, богатство, собственность. Информация заняла приоритетные позиции, определив зависимость существующих социокультурных структур, во многом именно это способствовало стиранию различий в отношении «центр-периферия». Ж. Бодрийяр в работе «Символический обмен и смерть» отмечает в этой связи, что информационное общество обретает за счет интенсивного роста информационных потоков знаковый, символический характер, редкостную активность движения. Информация формирует и информационную культуру как новое культурное состояние. Этим новым состоянием нужно управлять. Уже в первой половине XX века возникли сегменты знания, используя потенциал которых можно было изменить многое в управленческой деятельности - кибернетика, теория информации, теория игр, теория принятия решений, теория стохастических процессов. В практику управления вошли «интеллектуальные технологии», линейное программирование, метод экстремальных стратегий, ориентированных на работу с большими множествами в условиях неопределенности. Возникли новые теории управления, - так называемые неклассические теории: «Управленческая неклассика характеризуется тем, что больше не имеет готовых рецептов, алгоритмов действия и решений, она, требует постоянного переосмысления и переопределения своих воздействий на практику управления. Со- 
временная культура управления требует постоянного рефлексивного самоосознания, принятия решений, основанных не на алгоритмах действия, но соответствующих конкретным и всегда различным ситуациям. Философия в середине XX века помогла управленческой практике обратить внимание и использовать методы математической техники в работе с системами «организованной сложности», к которым отнесла, в первую очередь, социокультурные системы. Она отрефлексировала математическую технику, как и все появившиеся к тому времени новые технологии, как новую методику по поиску управленческого алгоритма поведения людей. Оказалось, что оно может быть предсказуемым, как очертание треугольников в геометрии. Это была, конечно, утопия, о чем тогда предупреждал Д. Белл, но утопия давала конструктивный толчок в поисках специфики управления сложными процессами, к которым и относятся процессы развития культуры» [6, с. 19].

«Современный рынок труда стимулирует многообразие социальных страт, возникновение и рост новых профессий. Все это дробит - «демассифицирует» - современную культуру, актуализирует проблему уникальности человека и его культурного окружения. Информационный мир сложен в своей культурной многоцветности. Это означает, что современное общество в его дробности, признания уникальности, многоцветности, поликультурности не может быть управляемо в любом своем фрагменте с позиций единства и принципа централизации», - так обосновывает идею множественности и плюральности теорий управления современного типа Н.В. Чиркова [7, с. 20].

В границах и пределах классического философского мышления было сформировано представление об управлении как однонаправленном и одноцелевом действии. В концептуальной парадигме Ф. Тейлора это рациональная организация труда, оптимизация совершаемых работником операций, совершенствование рабочих навыков; в концепции М. Вебера акцент смещен на сегмент конфликтных ситуаций, на проблематику рациональных и бюрократических решений, принимаемых теми, кто управляет. Однако Э. Мэйо создал теорию человеческих отношений, обратив внимание на ту роль, которая обеспечивает в эффективном и результативном управлении учет человеческого фактора. И потому, что целью создания концепции Э. Мэйо был все-таки рост производительности труда, концепция Э. Мэйо вошла в разряд классических концепций-теорий.

Культурное состояние неклассической эпохи требовало новых теорий управления. Впервые о необходимости нового подхода к управлению заговорили Ж. Бодрийяр, Ж.-Ф. Лиотар, М. Фуко, воплотив этот подход в игровом видении мира и взглянув на игру как способ работы социокультурных практик. В один из принципов управления была превращена игра.

Являясь культурным артефактом (культура «возникает и развивается в игре») [8, с. 7], игра может быть определена как разновидность физической и интеллектуальной деятельности, лишенной прямой практической целесообразности и представляющая индивиду возможность самореализации, выходящей за рамки его актуальных социальных ролей. Й. Хёйзинга в работе «Ноmо ludens. В тени завтрашнего дня» раскрывает игровые принципы практически всех составляющих культуры и дает следующее определение игры: «Игра есть добровольное действие либо занятие, совершаемое внутри установленных границ места и времени по добровольно принятым, но абсолютно обязательным правилам с целью, заключенной в нем самом, сопровождаемое с чувством напряжения и радости, а также сознанием «иного бытия», нежели «обыденная» жизнь» [9, с. 41]. Об игре, - об эстетической сущности игры, - пишет в работе «Истина и метод» Х.-Г. Гадамер, утверждая «священную серьезность игры», «медиальный смысл» игры, «примат игры в отношении сознания играющего», считая целью игры «порядок и структуру самого игрового движения» и полагая, что игра всегда предполагает «другого» [9, с. 174].

Во второй половине XX в. игровая концепция стала достоянием философии и теории культуры, разработаны и классификации игр. Так Р. Кайо в исследовании «Человек, игра и игры» (1962 г.) выделяет такие виды игр, как соревнование, переодевания (маскировки), подражания, экстатические и игры риска. Позднее в 1968 г. Йельские постструктуралисты, являясь философами постмодернистской направленности, ввели принцип игры, исследуя игры в референтных мирах. Ж. Деррида пишет об играх повторения (игры «репетитивности»), играх различий (difference) и различений (difference). Последняя треть XX века ознаменовалась активным внедрением понятия «игра» в сферы далеко не игровых видов деятельности: появляются математическая «теория игр», игровое моделирование ситуаций, практики деловых игр. Игра интерпретируется как сфера деятельности и жизни. В Игре увидели символическую условность, именно эта условность представляла человеку играющему («Homo ludens» - термин, введенный Й. Хёйзингой) возможность в границах игры быть свободным.

И в то время как классическим концепциям управления был присущ предельно рационализированный подход к тому, что выступало в качестве объекта управленческого воздействия, в неклассических теориях управления были воплощены новые подходы к феномену управления, - одним из этих подходов и явился подход, в основание которого положено видение мирореальности как игры, а игры - как способа реализации потенциала социокультурных практик: игра была превращена в управленческий принцип. Новый взгляд на 
управление, проявившей себя в неклассических подходах к управлению, в совокупности неклассических концепций и теорий управления, формировался многосторонностью и многогранностью тех объектов, которыми предстояло управлять, и моральной интерпретацией этих объектов, подвижностью и неустойчивостью [10].

Неклассические теории зафиксировали в своем содержании и новые принципы-характеристики управления, в числе этих характеристик мы назовем гибкость управления его мгновенное реагирование на перемены и используемые в этих переменах инновации («креативный разрушитель» в определении Й. Шумпетера); эта гибкость связана с возможностью, в зависимости от ситуации, переформулировать целевую программу, со способностью идти на риск (в теорию управления во- шла в качестве необходимого сегмента теория риска). Необходимо назвать и утрату управлением принципа центрированности: управление испытало возможности сформулированного М. Фуко принципа «микрофизики власти», - рассеивания в мире фрагментарной, лишенной центра культуры. На смену этому ранее существовавшему принципу центрированности пришли принципы «партисипативности» и «периферийности», о которых пишет М. Фуко в работе «Право на смерть и власть над жизнью. По ту сторону знания, власти и сексуальности». Наконец, очень существенным для неклассики управления был и отказ от иерархии в структуре управления. Сложившаяся ситуация выглядит следующим образом: новые социокультурные условия меняют, корректируют практику управления, «работая» на создание новых теорий управления.

\section{ЛИТЕРАТУРА}

1. Хабермас Ю. Моральное сознание и коммуникативное действие. М.: Наука, 2000. 380 с.

2. Петренко Н.С. Некоторые аспекты концепции «хорошего общества» и понятие блага // Философские науки. 2001. № 4. С. $29-34$.

3. Россман В.И. Мистерия центра. Идентичность и организация социального пространства в современных традиционных обществах // Вопросы философии. 2008. № 2. С. 30-34.

4. Фуко М. Интеллектуалы и власть: Избранные политические статьи, выступления и интервью. М.: Праксис, 2006. 320 с.

5. Белл Д. Грядущее постиндустриальное общество. Опыт социального прогнозирования. М.: Академия, 1999. URL: https://doi. org/10.1080/00131727609336501

6. Бодрийяр Ж. Символический обмен и смерть. М.: Добросвет, 2000. 387 с.

7. Тоффлер 0. Метаморфозы власти. Знание, богатство и сила на пороге XXI века. М.: ACT, 2004. 672 c. URL: https://doi.org/10.1016/0016-3287(91)90090-0

8. Хёйзинга Й. Homo Ludens. Статьи по истории культуры. М.: Прогресс, 1997. 416 c. URL: https://doi.org/10.4324/9781315824161

9. Гадамер Х.-Г. Истина и метод. Основы философской герменевтики. М.: Прогресc, 1988. 174 c. URL: https://doi.org/10.1524/9783050050195.219

10. Федотова В.Г. Социальные знания и социальные изменения. М.: ИФ РАН, 2001. 285 с. 